\title{
EFEITO DA INCLUSÃO DE SOJA INTEGRAL EM RAÇÕES EXTRUSADAS NO DESEMPENHO DE JUVENIS DE PIAVUÇU (Leporinus macrocephalus L.)
}

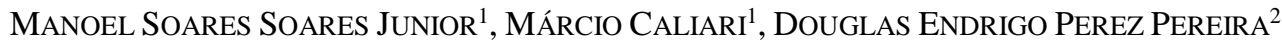

${ }^{1}$ Professores Doutores da Escola de Agronomia da Universidade Federal de Goiás, Goiânia, GO, Brasil ${ }^{2}$ Pós-Graduando em Biologia pela Universidade Federal de Goiás, Goiânia, GO, Brasil. douglasifb@hotmail.com

\begin{abstract}
RESUMO
Com este estudo objetivou-se avaliar o efeito da inclusão de soja integral em rações extrusadas com diferentes níveis de energia digestível na dieta de juvenis de piavuçu (Leporinus macrocephalus L.). Foram distribuídos 100 peixes com peso inicial de 5,06 $\pm 0,41 \mathrm{~g}$, em 20 aquários $(80 \mathrm{~L})$, num delineamento inteiramente casualizado com cinco tratamentos $(0 ; 20,0 ; 35,0 ; 50,0$ e $67,5 \%$ de soja integral nas dietas) e quatro repetições. Dietas isoprotéicas, isocálcicas, isofosfóricas, isoaminoácidicas para metionina e com diferentes valores de energia digestível $(3.193 ; 3.326 ; 3.413 ; 3.510$ e $3.621 \mathrm{kcal} / \mathrm{kg}$ )

foram fornecidas aos peixes durante setenta dias. Os seguintes critérios foram avaliados: peso final, ganho de peso, incremento em comprimento, consumo diário de ração, conversão alimentar, taxa de eficiência proteica e taxa de sobrevivência. Os tratamentos não diferiram $(\mathrm{P}>0,05)$ entre si em relação aos critérios avaliados. Concluiu-se que a inclusão de soja integral nas rações para juvenis de piavuçu é viável, podendo substituir parcial ou totalmente o farelo de soja, sem prejuízo de desempenho, embora proporcione maior deposição de gordura na carcaça.
\end{abstract}

PALAVRAS-CHAVE: alimento alternativo; Glycine max L.; energia digestível; nutrição; piscicultura.

\section{EFFECT OF SOYBEAN INCLUSION IN EXTRUDED RATIONS ON PERFORMANCE OF JUVENILE PIAVUÇU (Leporinus macrocephalus L.)}

\section{ABSTRACT}

The objective of this study was to evaluate the effects of the inclusion of extruded soybean in diets for piavuçu (Leporinus macrocephalus L.) juveniles with different levels of digestible energy. A hundred fish with initial weight of $5.06 \pm 0.61 \mathrm{~g}$ were distributed into 20 aquarium $(80 \mathrm{~L})$, in a entirely randomized design with five treatments $(0.00,20.00,35.00,50.00$ and $67.5 \%$ full fat soybean in the diets) and four replications. Isonitrogenous, isocalcium, isophosphorus, isoaminoacids for methionine diets with different digestible energy values $(3,193 ; 3,326$;
3,$413 ; 3,510$ and $3,621 \mathrm{kcal} / \mathrm{kg}$ ) were given to fish for seventy days. The criteria evaluated were weight gain, length increment, daily feed intake, feed gain, protein efficiency ratio and survival rate. No differences $(\mathrm{P}>0.05)$ were observed among treatments regarding the performance criteria. We concluded that the inclusion of full fat soybean in piavuçu juveniles diet is a viable option, and it may partially or totally replace soybean meal, without decreasing performance, while providing greater deposition of fat in the carcass.

KEYWORDS: alternative feedstuff; digestible energy; fish production; Glycine max L; nutrition. 


\section{INTRODUÇÃO}

A família dos Anostomídeos Characiformes é uma das mais complexas e o gênero Leporinus possui em torno de 60 espécies descritas, com ampla distribuição geográfica e de grande importância econômica, tanto para a pesca quanto para a exploração comercial. O piavuçu (Leporinus macrocephalus L.) tem grande potencial para a piscicultura por apresentar crescimento rápido, carne saborosa e rusticidade (NAVARRO et al., 2007; BITTENCOURT et al., 2010). Além disso, a espécie apresenta hábito alimentar onívoro e adapta-se com grande facilidade a dietas artificiais, o que a torna muito procurada para criações intensivas.

Para atender, de forma econômica, às exigências nutricionais das espécies cultiváveis, a aquicultura tem buscado fontes alternativas de ingredientes para a alimentação. Hábito alimentar, alimentos alternativos e necessidades nutricionais para o piavuçu foram estudados por FARIA et. al (2001), GALDIOLI et al. (2001), GONÇALVES et al. (2002), FURUYA et al. (2004), GENTELINI et al. (2005), SIGNOR et al. (2007) e FUNKLER et al. (2010), entre outros.

Os gastos com a alimentação correspondem à maior parte dos custos totais, podendo ultrapassar 50\% das despesas na cadeia produtiva na aquicultura intensiva (EL-SAYED, 1999), tornando relevante as pesquisas sobre o uso de alimentos alternativos. Para diminuição de custos, a possibilidade de reduzir os níveis de proteína da dieta tem sido estudada. Níveis altos de lipídios na dieta geralmente aumentam a conversão alimentar e a eficiência de fixação da proteína nos tecidos. Em dietas com baixa relação proteína:energia, a proteína é usada preferencialmente no crescimento e manutenção do corpo (WINFREE \& STICKNEY, 1981). A ação "economizadora de proteína" do lipídio já foi discutida para algumas espécies (VAN DER MEER, 1997), porém, ainda não foi estudada para o piavuçu.

O grão de soja, por conter elevado teor de proteína e energia, é boa alternativa de alimento proteico, apresentando cerca de 17 a $18 \%$ de óleo e 35 a $37 \%$ de proteína bruta de elevado valor biológico, com composição em aminoácidos essenciais favorável à alimentação de monogástricos, mas deficiente em metionina e treonina (BELLAVER et al., 2002). Por conter fatores antinutricionais que atuam negativamente no desempenho animal, a soja in natura não deve ser utilizada na alimentação de monogástricos sem que seja adequadamente processada (MENDES et al., 2004).

\section{Para RODRIGUES \& FERNANDES} (2006), peixes alimentados com dieta extrusada apresentam tendência de melhora nos índices de desempenho produtivo. O processo de extrusão de rações pode ser um meio para inativar fatores antinutricionais presentes na soja e resultar em aumento da digestibilidade dos nutrientes e da energia metabolizável (BELLAVER et al., 2002), com maior produtividade, redução dos custos e aumento da lucratividade na piscicultura (ROBINSON \& LI, 1995). Com essas premissas, desenvolveu-se este trabalho para investigar o efeito de dietas extrusadas com diferentes níveis de incorporação de soja integral e energia digestível sobre o desempenho e sobrevivência de juvenis de piavuçu.

\section{MATERIAL E MÉTODOS}

Foram utilizados 100 juvenis de piavuçu reproduzidos artificialmente e oriundos da mesma prole, com peso e comprimento médios de $5,06 \mathrm{~g} \pm 0,61 \mathrm{~g}$ e $7,30 \mathrm{~cm} \pm 0,43 \mathrm{~cm}$, respectivamente, obtidos na Universidade de Marília, Marília, SP.

O ensaio foi composto por cinco tratamentos, constituídos por dietas com níveis de incorporação de soja integral de $0,00 \%, 20,00 \%$, $35,00 \%, 50,00 \%$ e $67,5 \%$, sendo que houve quatro repetições por tratamento, com duração de 70 dias. As dietas foram fornecidas quatro vezes ao dia, à vontade, durante o período experimental, nos horários 10:00, 12:00, 14:00 e 16:00 horas.

As rações (Tabela 1) foram elaboradas no Laboratório de Extrusão da Faculdade de Engenharia de Alimentos da Universidade Estadual de Campinas, Campinas, SP. 
Tabela 1. Composição percentual e nutricional das rações experimentais com diferentes níveis de inclusão de soja integral

\begin{tabular}{lccccc}
\hline & \multicolumn{5}{c}{ Teor de inclusão de soja integral (\%) } \\
\cline { 2 - 6 } Ingrediente & 0 & 20 & 35 & 50 & 67,5 \\
\hline Farelo de soja & 50,00 & 35,00 & 24,00 & 13,00 & 0,00 \\
Milho & 46,16 & 41,18 & 36,98 & 33,08 & 28,56 \\
Soja integral & 0,00 & 20,00 & 35,00 & 50,00 & 67,5 \\
Fosbical & 2,82 & 2,70 & 2,90 & 2,80 & 2,82 \\
Premix ${ }^{1}$ & 1,00 & 1,00 & 1,00 & 1,00 & 1,00 \\
DL-Metionina & 0,00 & 0,10 & 0,10 & 0,10 & 0,13 \\
BHT & 0,02 & 0,02 & 0,02 & 0,02 & 0,02 \\
\hline Nutriente & & & & & \\
\hline Proteína Bruta (\%) & 28,00 & 28,00 & 28,00 & 28,00 & 28,00 \\
Extrato Etéreo (\%) & 2,10 & 5,00 & 7,00 & 9,10 & 11,60 \\
Fibra bruta (\%) & 2,70 & 2,70 & 2,70 & 2,70 & 2,70 \\
Cálcio (\%) & 0,80 & 0,80 & 0,80 & 0,80 & 0,80 \\
Metionina (\%) & 0,75 & 0,75 & 0,75 & 0,75 & 0,75 \\
Fósforo Total (\%) & 0,60 & 0,60 & 0,60 & 0,60 & 0,60 \\
\hline Energia Digestível (kcal.kg-1 $)$ & 3193 & 3326 & 3413 & 3510 & 3621 \\
\hline
\end{tabular}

${ }^{1}$ Os níveis de vitaminas e minerais garantidos por kg na embalagem do premix foram: ácido fólico=250 mg; ácido pantotênico=5.000 mg; vit. $\mathrm{A}=1.000 .000 \mathrm{UI}$; vit. $\mathrm{B} 1=250 \mathrm{mg}$; vit. $\mathrm{B} 12=2.500 \mathrm{mcg}$; vit. $\mathrm{B} 2=1.750 \mathrm{mg}$; vit. $\mathrm{B} 6=875 \mathrm{mg}$; vit. $\mathrm{C}=12.500 \mathrm{mg}$; vit. D3=600.000 UI; vit. E= $12.500 \mathrm{UI}$; vit. K=315 mg; niacina=3.750 mg; cobalto=24.999 mg; cobre=1.999 mg; ferro=11.249 mg; iodo $=106 \mathrm{mg}$; manganês $=3.749 \mathrm{mg}$; selênio $=75 \mathrm{mg}$; zinco $=17.499 \mathrm{mg}$; antioxidante $=0.25 \mathrm{~g}$.

As rações foram balanceadas utilizando-se os valores médios de nutrientes da Tabela de Composição dos Alimentos (ROSTAGNO et al., 2000) e as exigências nutricionais da tilápia do Nilo (NRC, 1983), formuladas para atenderem diferentes níveis de energia digestível (3.193,0; 3.326,0; $3.413,0 ; \quad 3510,0$ e $3.621,0$ kcal. $\left.\mathrm{kg}^{-1}\right)$ e ficarem isoprotéicas ( $28 \%$ de proteínas), isocálcicas $(0,8 \%$ de cálcio), isofosfóricas $(0,6 \%$ de fósforo total) e isoaminoacídicas para metionina $(0,75 \%)$, buscandose a substituição do farelo de soja pela soja integral e a não utilização de nenhum outro ingrediente, para a diminuição de custos.

O milho, os grãos de soja e o farelo de soja foram moídos separadamente em moinho de martelos até passarem por peneira de $0,5 \mathrm{~mm}$ de diâmetro. A homogeneização foi conduzida em misturador com capacidade de $30 \mathrm{~kg}$ por sete minutos. Essa mistura foi novamente moída e misturada por mais sete minutos, para melhorar a homogeneidade. As rações foram feitas com extrusor de laboratório de dupla rosca, co-rotacional, equipado com sistema de aquisição de dados on-line, alimentador volumétrico programável e bomba Watson-Marlon. As variáveis de processamento foram estabelecidas para cada ração, visando-se a otimização das suas características físicas, conforme descrito em SOARES JÚNIOR et al. (2004). A mistura de ingredientes foi colocada no alimentador volumétrico no início do processo. Os grânulos de ração foram cortados por um sistema de facas giratórias acoplado na saída do extrusor, sendo secos em estufa com circulação forçada de ar por 12 horas a $60^{\circ} \mathrm{C}$, resfriados à temperatura ambiente por 20 minutos, embalados em sacos de polipropileno e armazenados, em geladeira, a $5^{\circ} \mathrm{C}$, até serem utilizados.

Foram utilizados vinte aquários de fibra de vidro com dimensões de $50 \mathrm{~cm}$ x $50 \mathrm{~cm}$ x $50 \mathrm{~cm}$, água até o volume de $80 \mathrm{~L}$ e densidade de cinco peixes por unidade. Cada aquário foi equipado com um aquecedor e um aerador. Cada conjunto de três aquários (intercomunicantes) recebeu um filtro biológico e um sistema de alimentação e escoamento baseado em vaso comunicação para renovação contínua e constante de água, com vazão aproximada de $0,8 \mathrm{~L} \mathrm{~min}^{-1}$. Os aquários foram sifonados duas vezes por dia para remoção de fezes e eventuais sobras de rações, sendo, logo após, restabelecido o volume de água inicial. A temperatura da água foi aferida diariamente às 10:00 h e às 16:00 h com termômetro digital portátil. $\mathrm{O}$ nível de oxigênio dissolvido na água foi monitorado semanalmente usando-se a técnica de Winkler modificada pela adição de azida sódica, conforme descrito em BOYD (1984). O pH foi medido semanalmente com 
potenciômetro.

Avaliou-se o peso final, o ganho de peso, o incremento do comprimento, o consumo de ração, a conversão alimentar aparente, a taxa de eficiência proteica e a taxa de sobrevivência, segundo os métodos descritos em por JAUNCEY \& ROSS (1982), além da proporção de proteína bruta e de extrato etéreo no ganho de peso, segundo ALENCAR ARARIPE et al. (2011). Os teores de matéria seca, proteína bruta e extrato etéreo corporal dos alevinos de piavuçu foram determinados no início e no final do ensaio, segundo os métodos oficiais da AOAC (2005).

Os resultados foram avaliados com análise de variância e as médias foram comparadas com o teste Tukey ao nível de 5\% de probabilidade e os níveis de energia metabolizável submetidos à análise de regressão polinomial, com auxílio do programa SAS (2000).

\section{RESULTADOS E DISCUSSÃO}

Os valores de temperatura pela manhã e à tarde, de oxigênio dissolvido e de $\mathrm{pH}$ da água foram de $25,5 \pm 1,45^{\circ} \mathrm{C}, 26,4 \pm 1,56^{\circ} \mathrm{C}, 7,01 \pm 0,68 \mathrm{mg} \mathrm{L}^{-1}$ e $6,98 \pm 0,38$, respectivamente, ficando dentro dos limites para cultivo de peixes tropicais sugeridos por SIPAUBA-TAVARES (1994).

A sobrevivência dos piavuçus alimentados com todas as dietas foi de $100 \%$. O peso final, o ganho de peso, o incremento de comprimento, o consumo de ração, a conversão alimentar aparente, a eficiência da proteína, a matéria seca corporal, a proteína bruta corporal e a proporção de proteína bruta no ganho de peso não foram significativamente influenciados $(\mathrm{P}>0,05)$ pelo percentual de soja integral na dieta a $5 \%$ de probabilidade, ao contrário do extrato etéreo corporal e a da proporção de extrato etéreo no ganho de peso (Tabela 2). Os valores de ganho de peso dos alevinos de piavuçu obtidos nesta pesquisa superaram os obtidos por outros autores que trabalharam com esta espécie. Utilizando-se ração extrusada com $67,5 \%$ de soja integral foi obtido ganho de peso médio de 0,93 g.dia ${ }^{-1}$ ou $18,35 \%$, enquanto NAGAE et al. (2002) observaram valor máximo de 0,25 g.dia ${ }^{-1}$ com alevinos de peso inicial médio de $1,38 \mathrm{~g}$ durante 60 dias, utilizando rações peletizadas a frio constituídas de milheto em substituição ao milho. Embora, essas dietas possuíssem o mesmo teor de proteína, o valor energético foi inferior ao utilizado neste estudo. Já GONÇALVES et al. (2002), utilizando alevinos de piavuçu com peso inicial médio de $8,51 \mathrm{~g}$ e rações peletizadas a frio com $30 \%$ de proteína, $3000 \mathrm{kcal}$ e diferentes níveis de inclusão de farelo de canola na ração observaram ganho em peso máximo de $8,68 \%$ ao dia.

Tabela 2. Valores médios de desempenho e de matéria seca, proteína bruta e extrato etéreo corporal de juvenis de piavuçu (Leporinusmacrocephalus L.) em função das dietas com diferentes níveis de inclusão de soja integral durante 70 dias

\begin{tabular}{|c|c|c|c|c|c|c|c|}
\hline \multirow[t]{2}{*}{ Desempenho } & \multicolumn{5}{|c|}{ Teor de inclusão de soja integral (\%) } & \multirow{2}{*}{$\mathrm{CV}$} & \multirow{2}{*}{ Valor P } \\
\hline & 0 & 20 & 35 & 50 & 67,5 & & \\
\hline Peso final (g) & $52,3 \pm 7,8$ & $59,4 \pm 6,5$ & $60,6 \pm 17,3$ & $62,4 \pm 12,3$ & $70,1 \pm 13,9$ & 23,1 & 0,54 \\
\hline Ganho de peso (g) & $47,3 \pm 7,8$ & $54,3 \pm 6,5$ & $55,6 \pm 17,3$ & $57,4 \pm 12,3$ & $65,0 \pm 13,9$ & 25,3 & 0,54 \\
\hline Ganho de peso (\%) & $934,6 \pm 153,9$ & $1073,8 \pm 128,6$ & $1098,5 \pm 342,2$ & $1134,0 \pm 242,3$ & $1284,8 \pm 276,1$ & 25,3 & 0,54 \\
\hline $\begin{array}{l}\text { Incremento comprimento } \\
(\mathrm{cm})\end{array}$ & $8,7 \pm 0,7$ & $8,7 \pm 0,2$ & $8,8 \pm 1,8$ & $9,54 \pm 0,8$ & $10,2 \pm 1,2$ & 14,1 & 0,40 \\
\hline Consumo ração (g) & $56,6 \pm 6,8$ & $58,34,5$ & $63,0 \pm 4,0$ & $66,32 \pm 5,42$ & $66,4 \pm 9,1$ & 10,2 & 0,17 \\
\hline Conversão alimentar aparente & $1,1 \pm 0,2$ & $1,1 \pm 0,1$ & $1,0 \pm 0,5$ & $1,02 \pm 0,20$ & $1,0 \pm 0,1$ & 14,3 & 0,78 \\
\hline Eficiência proteína & $3,0 \pm 0,4$ & $3,2 \pm 0,2$ & $3,4 \pm 0,9$ & $3,18 \pm 0,52$ & $3,3 \pm 0,4$ & 7,9 & 0,78 \\
\hline Matéria seca $\left(\mathrm{g} .100 \mathrm{~g}^{-1}\right)$ & $16,94 \pm 1,8$ & $17,11 \pm 1,5$ & $17,86 \pm 0,7$ & $16,79 \pm 1,9$ & $17,80 \pm 1,2$ & 8,1 & 0,77 \\
\hline $\begin{array}{l}\text { Proteína bruta corporal } \\
\left(\mathrm{g} .100 \mathrm{~g}^{-1}\right)\end{array}$ & $9,51 \pm 1,1$ & $8,90 \pm 0,6$ & $9,53 \pm 0,6$ & $8,63 \pm 0,9$ & $8,63 \pm 0,5$ & 8,9 & 0,31 \\
\hline $\begin{array}{l}\text { Extrato estéreo corporal } \\
\left(\mathrm{g} .100 \mathrm{~g}^{-1}\right)\end{array}$ & $5,03^{\mathrm{B}} \pm 0,47$ & $6,37^{\mathrm{AB}} \pm 0,6$ & $6,60^{\mathrm{AB}} \pm 0,8$ & $6,74^{\mathrm{AB}} \pm 0,9$ & $7,59^{\mathrm{A}} \pm 1,4$ & 18,0 & 0,02 \\
\hline $\begin{array}{l}\text { Proteína bruta no ganho de } \\
\text { peso }\end{array}$ & $9,99 \pm 1,2$ & $9,25 \pm 0,7$ & $10,0 \pm 0,9$ & $9,0 \pm 1,0$ & $8,9 \pm 0,6$ & 10,0 & 0,28 \\
\hline $\begin{array}{l}\text { Extrato etéreo no ganho de } \\
\text { peso }\end{array}$ & $5,51^{\mathrm{B}} \pm 0,5$ & $6,91^{\mathrm{AB}} \pm 0,7$ & $7,23^{\mathrm{AB}} \pm 1,1$ & $7,38^{\mathrm{AB}} \pm 1,0$ & $8,16^{\mathrm{A}} \pm 1,5$ & 18,1 & 0,03 \\
\hline
\end{tabular}


Os maiores valores em ganho de peso obtidos neste trabalho provavelmente se devem ao processamento da ração, pois a tecnologia de extrusão permite a obtenção de grânulos de ração com maior estabilidade na água, maior integridade física e com formato e tamanho adequados ao tamanho do peixe, além de realizar a inativação de inibidores e a gelatinização do amido, melhorando a digestibilidade do produto (VIOLA et al., 1983; KIANG, 1999; SOARES JÚNIOR et al., 2004). Além do mais, a utilização da soja integral permitiu o aumento do valor energético das rações.

Para viabilizar o uso da soja integral crua em rações extrusadas é importante diminuir o tempo entre a moagem do grão da soja e a extrusão da ração. Assim, evitam-se reações químicas indesejáveis, como a ação das lipases e lipoxigenases sobre os triacilglicerídeos liberados do interior das células vegetais durante o intervalo entre essas operações.

Os peixes atingiram comprimentos finais entre 15,99 a 17,55 cm (Tabela 2). Esses valores são superiores aos observados por NAGAE et al. (2002), que obtiveram variação entre 9,82 a $10,39 \mathrm{~cm}$ quando avaliaram a inclusão do milheto nas rações de piavuçu, e aos verificados por NAGAE et al. (2001), com variação entre 9,07 a $9,61 \mathrm{~cm}$ para comprimento total, ao estudarem a inclusão de triticale nas rações para alevinos de piavuçu com peso inicial médio de $1,70 \pm 0,03 \mathrm{~cm}$ por um período de 60 dias. Em comparação com estudos realizados com outras espécies, ZEITLER et al. (1984) observaram a maior taxa de crescimento de carpa comum (Cyprinus carpio L.) ao incrementar a ração com energia digestível, independentemente do nível de proteína utilizado. VIOLA et al. (1983) relataram que o uso de óleo suplementar na ração de tilápia do Nilo (Oreochromis niloticus) não afetou significativamente o ganho em crescimento e a eficiência alimentar, em contraste a peixes como a carpa comum (Cyprinus carpio L.), truta arco-iris (Oncorhynchus mykiss) e o bagre-do-canal americano (Ictalurus puntatus), que utilizam o óleo suplementar de forma eficiente.

O consumo de ração das rações testadas permitiu afirmar que não houve rejeição a nenhuma delas. No tratamento controle o consumo de ração foi em média $16 \%$ menor que no tratamento com $67,5 \%$ de soja integral (Tabela 2). No experimento com piavuçu, conduzido por GONÇALVES et al. (2002), os valores reportados foram menores e variaram entre 41,10 a 43,5 g, enquanto FURUYA et al. (2004), usando farelo de soja integral em substituição ao farelo de soja em dietas para juvenis de tilápia do Nilo (peso inicial médio de
$1,58 \pm 0,06 \mathrm{~g}$ ) durante 45 dias, constataram valores de consumo que variaram entre 13,14 a 16,23 g.

A conversão alimentar variou entre 1,01 (com 67,5\% de soja integral) e 1,14 (tratamento controle), ou seja, quase $13 \%$ (Tabela 2). FARIA et al. (2001) estudaram dietas com substituição parcial ou total de farinha de peixe pelo farelo de soja para alevinos de piavuçu com peso inicial médio de 0,52 g no período de 62 dias e observaram variação entre 1,11 e 1,32 na conversão alimentar. Para a ração formulada com farelo de soja e sem farinha de peixe, os autores observaram valores de conversão alimentar similar aos obtidos neste trabalho.

HANLEY (1991) alimentou tilápias jovens com rações contendo 5\%, 9\% e $12 \%$ de lipídios e observou que o aumento no conteúdo de lipídios na ração não produziu efeito significativo sobre a taxa de crescimento, taxas de conversão alimentar e de eficiência da proteína, concordando com os resultados obtidos neste estudo com piavuçu, em que os teores de lipídeos variaram entre 2,1 a 11,6\% e a diferença entre os efeitos dos tratamentos não foi significativa.

A taxa de eficiência proteica das rações utilizadas neste ensaio variaram entre 3,00 e 3,36, sendo esses valores maiores que os obtidos nos trabalhos de GALDIOLI et al. (2001), NAGAE et al. (2001), FARIA et al. (2001) e FURUYA et al. (2004), e dentro da faixa de valores obtidos por GONÇALVES et al. (2002). VAN DER MEER et al. (1997) também verificaram o efeito do nível de lipídio na dieta na utilização de proteína em juvenis de tambaqui (Colossoma macropomum), observando que o crescimento e a eficiência da utilização da proteína aumentaram com o nível de lipídio da ração.

A matéria seca média dos alevinos de piavuçu determinada no início do ensaio foi de 8,04 g. $100 \mathrm{~g}^{-1}$, a proteína bruta corporal foi de 5,12 g. $100 \mathrm{~g}^{-1}$ e o extrato etéreo corporal foi de $0,65 \mathrm{~g} \cdot 100 \mathrm{~g}^{-1}$. Após dez semanas, tempo de duração do ensaio, esses valores elevaram-se entre 108 e 122\%, 69 e $86 \%$ e 674 e 1068\%, respectivamente. As dietas não afetaram o teor de matéria seca e a proteína bruta corporal, mas, sim, o teor de extrato etéreo corporal, que variou $51 \%$ entre a dieta com zero e $67,5 \%$ de soja integral (Tabela 2). O tratamento sem soja integral diferiu daquele com $67,5 \%$, enquanto os demais tratamentos não diferiram entre si nem dos demais. A proteína bruta no ganho de peso variou apenas $12 \%$ entre os tratamentos, enquanto que o extrato etéreo no ganho de peso foi influenciado pela dieta, variando $48 \%$ (Tabela 2). O tratamento sem soja integral diferiu daquele com $67,5 \%$, enquanto os demais tratamentos não diferiram entre si nem dos demais. HANLEY 
(1991) observou, em um experimento com tilápias, que o aumento do nível de lipídios na ração não mudou significativamente o teor de umidade e proteína dos peixes, mas elevou significativamente o teor de lipídios da carcaça e nas vísceras. A porcentagem de gordura na carcaça e a taxa de deposição de gordura no ganho de peso aumentou $(p<0,001)$ de forma linear em razão da elevação do nível de energia na dieta de piavuçu em fase póslarval (NAVARRO, 2007). VIOLA et al. (1988) também observaram que as tilápias que receberam ração com óleo suplementar em relação às que receberam ração basal somaram $40 \%$ de deposição de gordura a mais na carcaça, o que concorda com os valores verificados no presente trabalho.

\section{CONCLUSÕES}

Conclui-se que a inclusão de soja integral nas rações para juvenis de piavuçu é viável, podendo substituir parcial ou totalmente o farelo de soja, sem prejuízo de seu desempenho, mesmo com níveis energéticos mais altos, embora proporcione maior deposição de gordura na carcaça.

\section{AGRADECIMENTOS}

\section{À Capes pela concessão da bolsa de} doutorado.

\section{REFERÊNCIAS}

ALENCAR ARARIPE, M. N. B. de; ALENCAR ARARIPE, H.G.; LOPES, J.B.; CASTRO, P.L.; BRAGA, T.E.A.; FERREIRA, A.H.C.; ABREU, M.L.T.D. de Redução da proteína bruta com suplementação de aminoácidos em rações para alevinos de tambatinga. Revista Brasileira de Zootecnia, v.40, n.9, p.1845-1850, 2011.

ANDRIAN, I.F.; DÓRIA, C.R.C.; TORRENTE, G. Espectro alimentar e similaridade na composição da dieta de quatro espécies de Leporinus (Characiformes, Anostomidae) do rio Paraná $\left(22^{\circ} 10^{\prime}-22^{\circ} 50^{\prime} \mathrm{S} / 53^{\circ} 10^{\prime}\right.$ $\left.53^{\circ} 40^{\prime} \mathrm{W}\right)$, Brasil. Revista UNIMAR, v.16, n.3, p.97-106, 1994.

AOAC - ASSOCIATION OF OFFICIAL ANALYTICAL CHEMISTS. Official methods of analysis of AOAC International: Food composition, additives, natural contaminants. 18 ed., v. 2, Gaithersburg: AOAC International, 2005.

BELlAVER, C.; COTREFAL, G.; GRECCO, M. Soja integral: processamento e uso. Alimentação Animal, v.7, p.28-30, 2002.

BITTENCOURT, F.; FEIDEN, A.; SIGNOR, A.A.;
BOSCOLO, W.R.; FREITAS, J.M.A. Proteína e energia em rações para alevinos de piavuçu. Revista Brasileira de Zootecnia, v. 39, n.12, p.2553-2559, 2010.

BOYD, C.E. Water quality in warmwater fish ponds. 3 . ed. Alabama: Auburn University, 359p., 1984.

EL-SAYED, A.F.M. Alternative dietary protein sources for farmed tilapia, Oreochromis spp. Aquaculture, v.179, p.149-168, 1999.

FARIA, A.C.E.A.; HAYASHI, C.; SOARES, C.M. Substituição parcial e total da farinha de peixe pelo farelo de soja em dietas para alevinos de piavuçu, Leporinus macrocephalus (Garavello \& Britski, 1988). Acta scientiarum, v.23, n.4, p.835-840, 2001.

FUNKLER, J.K.; FREITAS, J.M.A.; SIGNOR, A.A.; ZAMINHAM, M.; BOSCOLO, W.R.; FEIDEN, A. Substituição da farinha de peixe por farinha de vísceras de aves na alimentação de alevinos híbridos de piavuçu (Leporinus macrocephalus) e piapara (Leporinus elongatus). Boletim do Instituto de Pesca, v.36, n.3, p.237-243, 2010.

FURUYA, W.M.; HAYASHI, C.; FURUYA, V.R.B. SAKAGUTI, E.S.; BOTARO, D.; SILVA, L.C.R.; AURESCO, S.A. Farelo de soja integral em rações para juvenis de tilápia do Nilo (Oreochromis niloticus). Acta Scientarum, Animal Science,v.26, n.2, p.203-207, 2004.

GALDIOLI, E.M.; HAYASHI, C.; FARIA, A.C.E.A.; SOARES, C.M. Substituição parcial e total da proteína do farelo de soja pela proteína dos farelos de canola e algodão em dietas para alevinos de piavuçu (Leporinus macrocephalus). Acta Scientiarum, Animal Science, v.23, n.4, p.841-847, 2001.

GARAVELLO, J.C. \& BRITSKI, H.A. Leporinus macrocephalussp da bacia do rio Paraguai. Naturalia, v.13, n.1, p.67-74, 1988.

GENTELINI, A.L.; BOSCOLO, W.R.; FEIDEN, A. Graus de moagem dos ingredients em rações peletizadas para alevinos de piavuçu (Leporinus macrocephalus), Brasil. Acta Scientiarum, Animal Science, v.27, n.1, p.93-97, 2005.

GONÇALVES, G. S.; FURUYA, W. M.; RIBEIRO, P. R. Farelo de canola na alimentação do piavuçu, Leporinusmacrocephalus (Garavello\&Britski), na fase inicial. Acta Scientiarum, Animal Science, v.24, n.4, p.921-925, 2002.

HANLEY, F. Effects of feeding supplementary diets containing varyng levels of lipid on growth, food conversion, and body composition of Nile tilapia, Oreochromis niloticus (L.). Aquaculture, v.93, p.323$334,1991$.

KIANG, M-J. Principles of aquaculture feed production by cooking extruder. In: CHANG, Y. K.; WANG, S. S. (eds.). Advances in extrusion technology. Lancaster: Technomic Co. Inc. p.107-113. 1999.

MENDES, W.S.; SILVA, I.J.; FONTES, D.O. Composição química e valor nutritivo da soja crua e 
submetida a diferentes processamentos térmicos para suínos em crescimento. Arquivo Brasileiro de Medicina Veterinária e Zootecnia, v.56, n.2, p.207-213, 2004.

NAGAE, M.Y.; HAYASHI, C.; GALDIOLI, E.M. Inclusão do triticale em rações para alevinos de piavuçu, Leporinus macrocephalus (GARAVELLO \& BRITSKI, 1988), Brasil. Acta Scientiarum, Animal Science, v.23, n.4, p.849-853, 2001.

NAGAE, M.Y.; HAYASHI, C.; SOARES, C.M. Inclusão do milheto (Pennisetum americanum) em rações para alevinus de piavuçu (Leporinus macrocephalus). Revista Brasileira de Zootecnia, v.31, n.5, p.1875-1880, 2002.

NRC. Nutrient requirements of warmwater fishes and shellfishes. Washigton: National Academy Press, 1983. 102 p.

NAVARRO, R. D.; LANNA, E. A. T.; DONZELI, J. L.; MATTA, S. L. P.; SOUZA, M. A. Níveis de energia digestível da dieta sobre o desempenho de piavuçu (Leporinus macrocephalus) em fase pós-larval. Acta Scientarum, Animal Science, v.29, n.1, p.109-141, 2007.

RODRIGUES, L.A. \& FERNANDES, J.B.K. Influência do processamento da dieta no desempenho produtivo do acará bandeira (Pterophyllum scalare). Acta Scientiarum, Animal Science, v.28, n.1, p.113-119, 2006.

ROSTAGNO, H.S.; ALBINO, L.F.T.; DONZELE, J.L. Composição de alimentos e exigências nutricionais de aves e suínos: Tabelas Brasileiras, Viçosa, MG: Universidade Federal de Viçosa, 2000. 141p.

ROBINSON, E.H. \& LI, M.H. Catfish nutrition part III: feed manufacture. Aquaculture Magazine, v.21, p.57-64, 1995.

SAS. Statistical Analysis System - User's Guide. Version

\section{1, Cary: 2000}

SIGNOR, A.A.; BOSCOLO, W.R.; FEIDEN, A.; REIDEL, A.; SIGNOR, A.; GROSSO, I.R. Farinha de vísceras de aves na alimentação de alevinos de piavuçu (Leporinus macrocephalus). Ciência Rural, v.37, n.3, p.828-834, 2007.

SIPAUBA-TAVARES, L.M. Limnologia aplicada à aquiicultura. Jaboticabal: Funep, 1992. 70 p.

SOARES JÚNIOR, M.S.; CALIARI, M.; CHANG, Y.K. Substituição de farelo de soja por soja integral em rações extrusadas para aqüicultura. Pesquisa Agropecuária Tropical, v.34, n.1, p.29-37, 2004.

VAN DER MEER, M.B.; ZAMORA, J.E.; VERDEGEM, M.C.J. Effect of dietary lipid level on protein utilization and the size and proximate composition of body compartiments of Colossom amacropomum (Curvier). Aquaculture Research, v.28, p.405-417, 1997.

VIOLA, S.; MOKADY, S.; ARIELI, Y. Effects of soybean processing methods on the growth of carp (Cyprinus carpio). Aquaculture, v.32, p.27-38, 1983.

VIOLA, S.; MOKADY, S.; BEHAR, D.; COGAN, U. Effects of polyunsaturated fatty acids in feeds of tilapia and carp. 1. Body composition and fatty acid profiles at different environmental temperatures. Aquaculture, v.75, p.127-137, 1988.

WINFREE, R.A. \& STICKNEY, R.R. Effects of dietary protein and energy on growth, feed conversion efficiency and body composition of Tilapia aurea. Journal of Nutrition, n.111, p.1001-1012, 1981.

ZEITLER, M.H.; KIRCHGESSNER, M.; SCHWARZ, F.J. Effects of different protein and energy supplies on carcass composition of carp (Cyprimus carpio L.). Aquaculture, v.36, p.37-48, 1984. 